\title{
Sexology in Portugal: Narratives by Portuguese Sexologists
}

\section{Violeta Alarcão, Ana Beato, Joana Almeida, Fernando Luís Machado \& Alain Giami}

To cite this article: Violeta Alarcão, Ana Beato, Joana Almeida, Fernando Luís Machado \& Alain Giami (2015): Sexology in Portugal: Narratives by Portuguese Sexologists, The Journal of Sex Research, DOI: 10.1080/00224499.2015.1104286

To link to this article: http://dx.doi.org/10.1080/00224499.2015.1104286

曲 Published online: 18 Dec 2015.

Submit your article to this journal $\pi$

Џll Article views: 13

Q View related articles $\sqsubset$

View Crossmark data $\nearrow$ 


\title{
Sexology in Portugal: Narratives by Portuguese Sexologists
}

\author{
Violeta Alarcão $\odot$, Ana Beato, and Joana Almeida \\ Institute of Preventive Medicine and Public Health, Faculty of Medicine, University of Lisbon \\ Fernando Luís Machado \\ Centre for Research and Studies in Sociology, University Institute of Lisbon
}

\author{
Alain Giami \\ Institut de la Santé et de la Recherche Médicale (Inserm), Paris/Le Kremlin-Bicêtre
}

\begin{abstract}
This article presents the emergence and development of modern sexology in Portugal through the analysis of Portuguese sexologists' narratives, to explore how they commit to a professional identity as sexologists, and to discuss how they integrate their professional role into the vast multidisciplinary field of sexology. In-depth interviews were conducted with 44 key professionals, purposefully recruited to guarantee heterogeneity concerning generation, gender, training, and practice. Content analysis focused on highlighting differences and articulations among the main professionals making up the field. The findings indicate that sexology is not seen as a full-fledged profession but rather as a specialization or a secondary field of action. The sexual medicine perspective is prevalent and more visible among physicians, thus reflecting the gap between psychosocial and biomedical approaches. A close link between clinical work and research and a gap between clinical work and health promotion were found. Despite the multidisciplinary nature of sexology being acknowledged, it is not fully implemented by the experts in the field. However, it is this characteristic that permitted sexology to institutionalize and to legitimate itself as a discourse of truth about sex, in Portugal as in other countries.
\end{abstract}

Although sexology as a specific field of knowledge, a practice, and a profession appeared in the second half of the 19th century (Ariès \& Béjin, 1985; Bland \& Doan, 1999), the field remains controversial and challenged, as the multidisciplinary nature of sexology strongly contributes to its "outlaw" (Zucker, 2002) and "dirty" character (Irvine, 2014). The field of sexuality produces paradoxical cultural reactions. This led Irvine (2014) to study sexuality research as a form of "dirty work," an occupation that is simultaneously socially necessary and stigmatized, using Hughes's (1958, 1962) dirty work paradox, in which society disavows a type of work while at the same time recognizing it as a crucial form of labor. The constitution of sexuality research as dirty work has implications not only for the researchers who face barriers establishing academic legitimacy; it also affects the broad production of sexual knowledge and sexological practice (Irvine, 2014).

Sexology is an umbrella term used to represent the multidisciplinary activities of groups of researchers, clinicians,

Correspondence should be addressed to Violeta Alarcão, Epidemiology Unit of the Institute of Preventive Medicine and Public Health, Faculty of Medicine, University of Lisbon, Av. Professor Egas Moniz 1649-028, Lisbon, Portugal. E-mail: violeta.alarcao@gmail.com and educators related to sexuality (Irvine, 2005). However, sexology and sex therapy - and, more recently, sexual medicine-are not practiced all in the same way in different cultures or even in Western culture. Variations in professional practices of sexology relate to national and cultural contexts, training, organization of health services, and professional motivation (Fruhstuck, 2003; Giami, 2012; Kontula, 2011). In this study, the term sexologist is used to describe people with different degrees and levels of training who work as physicians, psychologists, nurses, midwives, therapists, educators, and researchers, in settings that can range from universities to nongovernmental organizations (NGOs), health care, hospitals, government entities, and private practice, and who contribute directly or indirectly to the sexology perspective. Many professionals do not recognize themselves as sexologists, and the profession of sexology is still not completely recognized as an autonomous profession by public health authorities in most European countries (Giami, 2012).

Sexual science was first developed in Western Europe and was centered in Germany until the Nazi persecution (Haeberle, 1981). In the United States, it was developed by the middle of the 20th century, and it has historically been a domain of stigma and immorality in Western societies 
(Bancroft, 2004). This factor explains why sexology, as a profession, remains "relatively obscure" and why the "sex expert" is still often the object of parody and sometimes rejection (Irvine, 2005). Nevertheless, sexology has increasingly grown from 20th-century social transformations and sexuality modernization, contributing to the progressive achievement of sexual rights (Giami, 2015; Parker et al., 2004) and toward the legitimacy of a sexuality focused on pleasure as a means of individual self-realization (Giddens, 1992).

\section{Focus and Research Questions}

This article focuses on describing and analyzing the characteristics of the scientific and professional organization of Portuguese sexology through Portuguese sexologists' self-descriptions and reflections on this ongoing process. How did Portuguese sexologists build a professional identity, and how did they integrate their professional role into the vast multidisciplinary field of sexual health? The interpretation of the diversity of meanings attributed to the identity of sexologist was linked with the different positions held by the participants in the field and related to gender and professional category (physicians and nonphysicians). A discussion of some of the challenges facing the evolution of the field is presented using sexologists' own words, when possible, as most Portuguese sexology founders are still working in the field, along with other new recognized figures.

In this article, the diversity of sexologies among European countries is first outlined. Second, social, first cultural, and political factors linked to the emergence of sexology in Portugal are briefly contextualized, followed by identification of the institutional factors that have boosted its professionalization. Then the methodological procedures that guided the analysis of different modes of identification of sexologists are detailed. Third, the empirical information resulting from 44 in-depth interviews with key professionals is described. Finally, the social and symbolic relevance of the emerging profession of sexologist in Portugal is discussed, and some implications arising from this professional development for the role of sexology as a science and profession in general are briefly outlined.

\section{The Diversity of Professional Sexologists in Europe}

Since 1998 the Euro-Sexo study group has been characterizing sexologists in particular European countries and comparing data (Giami \& de Colomby, 2003; Wylie, de Colomby, \& Giami, 2004). Thus, seven national Western European contexts were described using the same questionnaire (Denmark, Finland, France, Italy, Norway, Sweden, and the United Kingdom) during the past decade; however, Portugal and Spain were not yet included (Giami \& de Colomby, 2006).

The diversity of professional profiles in general sexology practice across countries is interesting to observe (Giami \& de
Colomby, 2006). For example, in Finland (Kontula \& Valkama, 2006) and in the United Kingdom (Wylie et al., 2004), the nursing professions have prevailed, which is different from Portugal, Italy (Simonelli, Fabrizi, Rossi, Corica, \& Giami, 2006), and Norway (Almaas \& Giami, 2006), where midwives and nurses are much less frequently represented. Midwives are a large and important group participating in sexology in Sweden (Fugl-Meyer \& Giami, 2006), but they are almost non-existent in Portugal. General practitioners are prominent in France (Giami \& de Colomby, 2003) and Denmark (Kristensen \& Giami, 2006) but they are less represented elsewhere - just like in Portugal, where other professions such as teachers, social workers, occupational therapists, or physiotherapists, are also very short in numbers. The diversity of professions involved in the practice of sexology may explain the internal tensions of the field and justify why the institutional contexts and cultural understanding of sexuality need to be investigated (Hall \& Graham, 2012).

The field of sexology, the definition of a sexologist, and the pathway leading to the professional practice of sexology and sex therapy are still unexplored in Portugal. Sexuality studies is inherently interdisciplinary, and the multidisciplinarity of the professionals in the field represents a real challenge to this investigation. The members of the different professions differ in their characteristics and specificities, which are historically and geographically shaped. They occupy diverse hierarchical positions and obtain different levels of prestige, power, jurisdiction, and authority (Freidson, 1988). This heterogeneity has been present since the origin of Portuguese sexology. There is no clear and set path to become a sexologist in Portugal. There is no consensus either on the definition of a sexologist or an enunciation of its competencies and an accurate description of their tasks.

\section{Sexology in Portugal: Social, Cultural, and Political Challenges}

The Portuguese experience of sexuality was shaped in part by a 48-year dictatorship (1926-1974), which kept Portugal at the margins of the European social and legal transformations that contributed to deep changes in gender relations, family lifestyles, and the acceptance of different sexual orientations and gender identities. Political and legal concerns about lesbian, gay, bisexual, and transgender (LGBT) rights took place only in the 1990s as a corollary to human immunodeficiency virus/acquired immunodeficiency syndrome (HIV/AIDS) activism. In the Portuguese case, especially among physicians and patients, these were linked to the economic and social development of the country and, consequently, to mentality change (Almeida, 2010).

Concerning the legal landmarks for understanding the context of the emerging field of sexology and sexuality in Portugal, the first major moment in contemporary history was the democratic revolution of April 25, 1974, and the Constitution of 1976, which legitimized a number of 
important rights and guarantees and allowed for a progressive transformation of practices. The second event, which occurred in 1982, was the decriminalization of homosexuality, and it was also linked to the emergence of other claims. In the 21 st century, the law of cohabitation in 2001 was in fact a landmark for being an inclusive law, which extended to same-sex couples the same rights as opposite-sex couples living in a de facto union for more than two years. The revision of the Constitution in 2004 was especially important, as it made Portugal the first European country and the fourth worldwide to prohibit discrimination based on sexual orientation in its Constitution. The decriminalization of abortion in 2007 represents a recent legal milestone with a social and political debate that is still ongoing in Portugal. In 2010, Portugal became the sixth country in Europe and the eighth country in the world to allow same-sex marriage nationwide, but it became the only country in the world where same-sex marriage is allowed without parenting rights. In 2011, the Law of Gender Identity was ratified, which simplified the process of sex and name change for transsexual people. Finally, the most recent ongoing discussion in Portugal is the "coadoption" of the biological or adopted child of the same-sex spouse or partner, wherein that spouse or partner is the only legally recognized parent of the child.

Indeed, some of the most significant changes in the Portuguese sexuality field that highlight a tremendous contrast between the past and present took place among the dissociation of reproductive and erotic sexual activities, the possibilities of nonmarital sexual activity, and the reconstruction of nonbinary standards for gender identity (Aboim, 2013). As in many countries, sexologists played a relevant role in managing sexual diversity in Portugal.

\section{Emergence and Institutionalization of Sexology in Portugal}

The first phase of Portuguese contemporary sexology was characterized by having two groups of actors and two separate paths: through gynecology and through psychiatry. The initial connection of gynecology to family planning and sexual and reproductive health was particularly important in Portuguese society in the $1960 \mathrm{~s}$. Populations lived in a situation of extreme poverty with high rates of maternal and infant mortalities, a high prevalence of clandestine abortion, and the absence of contraceptive methods and family planning services. With the legitimation of sexual rights and sexuality for pleasure, presently a few gynecologists are dedicated to the study of the sexual function and satisfaction. The Family Planning Association (APF: Associação para o Planeamento da Família) marks the emerging phase of sexual and reproductive health in Portugal and currently remains a reference association in this area, having an active role in the development and implementation of sexual and reproductive health policies and sexual health education, namely through sex education in schools and the creation of services for young people (Vilar, 2009).

Clinical sexology started in public hospitals in Coimbra, Oporto, and Lisbon in the late 1960s, and especially after the restoration of democracy in 1974, by some psychiatrists interested in implementing Masters and Johnson's work and training for other professionals and research development (Albuquerque, 2010). Most of the pioneering psychiatrists are still prominent figures in the field of sexology and are particularly linked to its postgraduate education.

In the second phase of Portuguese sexology, two groups of key actors, urologists and psychologists, with a common path, focused on the physiological and psychological research of sexual functioning, and this can be characterized as the second generation of Portuguese sexologists. This period was also marked by the affirmation of sexology as a science of sexuality, which is the first step toward its academic legitimacy. SPSC (Sociedade Portuguesa de Sexologia Clínica, the Portuguese Clinical Sexology Association) has granted the sexual therapist title since 1995 for those who have a medical degree or a clinical psychology background and have undertaken the two-year training program offered in that association. Other institutions offer academic but not professional certification, such as masters' degrees (Kontula, 2011). Nevertheless, the practice of sexology is little institutionalized in terms of control and protection of the title and the professional status of sexology, and professionals are willing to forgo the same, given that the titles of psychologist and, even more so, medical doctor transfer legitimacy enough, in Portugal as elsewhere (Giami, 2012).

In brief, the first period of the emergence and institutionalization of sexology in Portugal was guided above all by the national specificities that are associated with the cultural context of the country, such as the presence of family planning, the influence of the Catholic religion, and the interest of some professions such as gynecology, psychiatry, and psychology. In contrast, the most recent phase of sexology is marked by the medicalization and pharmaceuticalization of sexuality (Williams, Martin, \& Gabe, 2011), with a movement of homogenization of sexual medicine centered on the pharmacological treatment of sexual dysfunctions. Despite the dominance of sexual medicine, there is also the presence of the perspective of sexual health in the field of sexology in Portugal that is based on psychosocial and educational approaches and focuses on sexual rights, with the support of human rights organizations. This recent phase of Portuguese sexology coincides with the third wave of international sexology represented by sexual medicine, which came into being in the final decade of the 20th century (Russo, 2013).

\section{Method}

To understand and interpret the different modes of commitment to the larger professional identity of sexologist in 
Portugal, and produce knowledge about the meanings attributed to sexology, a qualitative study was carried out based on in-depth individual interviews with key players from the field. Selection criteria included (a) being founding members, former presidents, or active participants of an institution dealing with sexology; (b) being leading social science experts on sexuality with a role in the field of sexology; (c) being regarded by key participants as relevant actors in the field of sexology; and (d) being available and willing to be interviewed. Social scientists were included to broaden our view on the professional role of sexuality specialists and selected from those who addressed sexuality issues and often interacted with well-known sexologists, even if they did not acknowledge themselves as such, nor consider themselves part of the field of sexology. No restrictions of professional category or specific training in sexology were applied. Informants underwent an initial selection process whereby representatives of two generations of sexologists, considering their starting role in the field of Portuguese sexology (role in establishing the field of sexology), were identified. One main criterion for this division was training. The first generation did not receive any initial training in sexology in Portugal, but because they sowed the seeds of training institutions, the second generation did receive training in sexology.

\section{Participants}

Our sample selection followed a purposive strategy to cover different profiles of sexologists and to guarantee generation, gender, disciplinary, and practice diversity among actors in the field of sexology, and also to capture the tensions across the network of professionals. First, using the Google search engine, we carried out an overall mapping of sexology in Portugal, which included creating a directory of a heterogeneous group of associations, societies, institutes, clinics, NGOs, research groups, and professionals linked to sexology, through which we could identify the key players in the field. Then the interviewees indicated other key professionals, who were also included. A total of 55 sexology and/or sexual medicine key professionals/ experts in clinical practice, research and teaching, sex education, health promotion, and public media fields were identified. Among those, five were not contactable; five accepted but we could not schedule the interview; and one explicitly refused to participate. Thus, the purposeful sample was made up of 26 men and 18 women: of these, 22 were physicians; and among the other 22 nonmedical professionals 13 were psychologists, and nine were social scientists.

Table 1 shows the interviewed key professionals' characteristics of the first generation, considering their starting role in the Portuguese sexology field. Therein, the first generation was made up of 13 men and no women (although two of the unscheduled interviews were women of the first generation); among those, seven were pioneers in the field. The pioneers are a group of founders of the field of sexology who had the role of creating sexual health clinical services, professional associations, journals and handbooks of the specialty, and informal training for the following generations. This group of founders played a key role in the construction of the professional identity, being consensually referred to by all other experts as central figures in the field. The second generation of 13 men and 18 women is presented in Table 2. As opposed to the first generation, nonmedical professionals represent the majority of the second generation, with 13 participating psychologists in this larger group.

\section{Procedures}

This study was approved by the appropriate ethic committee (Lisbon Faculty of Medicine), and permission from the Portuguese Protection Data Authority was obtained. To preserve anonymity, participants were attributed a code number in the survey, and information that could be used for the identification of participants (e.g., work/organization affiliation) was omitted. These measures were aimed at

Table 1. First Generation of Key Professionals Interviewed

\begin{tabular}{|c|c|c|c|c|c|}
\hline & Gender & Age & Area of Activity & Original Profession & Specialization in Sexuality \\
\hline 1 & M & $60-70 *$ & Oporto & Urologist & Clinical work \\
\hline 2 & M & $70-80 *$ & Lisbon & Psychiatrist & Clinical work \\
\hline 3 & M & $70-80 *$ & Lisbon & Endocrinologist & Clinical work, teaching, and research \\
\hline 4 & M & $70-80 *$ & Oporto & Psychiatrist & Clinical work \\
\hline 5 & M & $60-70$ & Lisbon & Endocrinologist & Clinical work and teaching \\
\hline 6 & M & $50-60$ & Lisbon & Social scientist & Teaching, research, and health promotion \\
\hline 7 & M & $50-60$ & Lisbon & Social scientist & Teaching and research \\
\hline 8 & M & $70-80 *$ & Coimbra & Psychiatrist & Clinical work and teaching \\
\hline 9 & M & $70-80 *$ & Lisbon & Urologist & Clinical work \\
\hline 10 & $\mathrm{M}$ & $60-70$ & Lisbon & Social scientist & Teaching and research \\
\hline 11 & M & $60-70 *$ & Oporto & Psychiatrist & Clinical work and teaching \\
\hline 12 & $\mathrm{M}$ & $50-60$ & Lisbon & Gynecologist & Clinical work, teaching, and research \\
\hline 13 & M & $50-60$ & Lisbon & Medical doctor & Health promotion \\
\hline
\end{tabular}

*Pioneer in the field. 
Table 2. Second Generation of Key Professionals Interviewed

\begin{tabular}{|c|c|c|c|c|c|}
\hline & Gender & Age & Area of Activity & Original Profession & Specialization in Sexuality \\
\hline 1 & $\mathrm{~F}$ & $30-40$ & Lisbon & Psychologist & Clinical work, teaching, and research \\
\hline 2 & $\mathrm{~F}$ & $30-40$ & Coimbra & Social scientist & Teaching, research, and health promotion \\
\hline 3 & $\mathrm{M}$ & $40-50$ & Lisbon & Endocrinologist & Clinical work and teaching \\
\hline 4 & $\mathrm{~F}$ & $40-50$ & Oporto & Psychologist & Clinical work and teaching \\
\hline 5 & $\mathrm{~F}$ & $50-60$ & Coimbra & Psychiatrist & Clinical work \\
\hline 6 & $\mathrm{~F}$ & $30-40$ & Lisbon & Psychologist & Clinical work and teaching \\
\hline 7 & $\mathrm{~F}$ & $30-40$ & Lisbon & Social scientist & Research and media \\
\hline 8 & M & $50-60$ & Lisbon & Endocrinologist & Clinical work and teaching \\
\hline 9 & M & $40-50$ & Lisbon & Psychologist & Clinical work and teaching \\
\hline 10 & M & $40-50$ & Lisbon & Endocrinologist & Clinical work and teaching \\
\hline 11 & $\mathrm{~F}$ & $40-50$ & Lisbon & Gynecologist & Clinical work and health promotion \\
\hline 12 & $\mathrm{~F}$ & $50-60$ & Lisbon & Gynecologist & Clinical work and media \\
\hline 13 & $\mathrm{~F}$ & $30-40$ & Lisbon & Psychologist & Clinical work, health promotion, and research \\
\hline 14 & $\mathrm{~F}$ & $40-50$ & Lisbon & Psychologist & Clinical work and teaching \\
\hline 15 & $\mathrm{~F}$ & $40-50$ & Lisbon & Gynecologist & Clinical work and health promotion \\
\hline 16 & $\mathrm{~F}$ & $30-40$ & Lisbon & Social scientist & Research and health promotion \\
\hline 16 & $\mathrm{~F}$ & $40-50$ & Lisbon & Psychologist & Clinical work and media \\
\hline 18 & M & $50-60$ & Lisbon & Social scientist & Teaching, research, and health promotion \\
\hline 19 & M & $50-60$ & Lisbon & Urologist & Clinical work, teaching, and research \\
\hline 20 & M & $30-40$ & Lisbon & Psychologist & Clinical work, teaching, and research \\
\hline 21 & $\mathrm{~F}$ & $30-40$ & Lisbon & Psychologist & Clinical work, teaching, and research \\
\hline 22 & M & $50-60$ & Lisbon & Medical doctor & Teaching and research \\
\hline 23 & M & $40-50$ & Lisbon & Social scientist & Teaching and research \\
\hline 24 & M & $40-50$ & Aveiro & Psychologist & Clinical work, teaching, and research \\
\hline 25 & M & $40-50$ & Oporto & Urologist & Clinical work, teaching, and research \\
\hline 26 & M & $40-50$ & Lisbon & Psychologist & Clinical work and media \\
\hline 27 & M & $60-70$ & Lisbon & Psychiatrist & Clinical work, teaching, and research \\
\hline 28 & $\mathrm{~F}$ & $30-40$ & Aveiro & Psychologist & Clinical work, teaching, and research \\
\hline 29 & $\mathrm{~F}$ & $30-40$ & Lisbon & Endocrinologist & Clinical work and teaching \\
\hline 30 & $\mathrm{~F}$ & $30-40$ & Lisbon & Social scientist & Teaching and research \\
\hline 31 & $\mathrm{~F}$ & $30-40$ & Algarve & Psychologist & Clinical work and media \\
\hline
\end{tabular}

honoring confidentiality agreements between participants and researchers.

The experts' invitations were made by e-mail and by phone, and interviews were booked on dates and places chosen by the interviewees. Most interviews were performed in private offices, and only a few were performed in public places that provided privacy; those were held by a sociologist and three psychologists knowledgeable in the field and who had training in qualitative research. The interviews took place between November 2011 and April 2012 and lasted between 45 minutes and 2 hours. The semistructured interview script was divided into three major areas to be completed: personal and professional trajectory; sexology as a profession; and the sexology field in Portugal.

Open questions were asked to identify how the interviewees defined themselves in a professional perspective and in the context of sexology, and what motivated their involvement in the sexology field and their professional path in the area, considering clinical work, research, education, and teaching. We also asked how each expert was related to other experts and sexology areas. In addition, we explored experts' perspectives about concepts such as sexology, human sexuality, sexual medicine, sex education, and sex therapy, and their integration, similarities, and distinctions. Finally, we asked about the future directions in clinical work, research, and education related to sexology.

\section{Data Analysis}

Interviews were audiotaped and transcribed with the participants' informed consent. The systematic examination of the whole dataset of interviews was carried out through the application of an objective coding scheme technique, content analysis.

At the first step, exploratory data analysis focused on identifying and describing the broad themes (such as professional trajectory, professional identity, profession frontiers, and collaboration with other fields), which were typed into an Excel spreadsheet. Then, a more detailed interpretative analysis was intended to capture the process of professional identification with sexology and participants' perceptions and experiences and the way they made sense of their activities in the field of sexology. At this stage, we followed a grounded theory approach with Charmaz's (2003) open-coding strategy. This method of conducting the analysis of data results in the identification of new categories and dimensions that goes beyond the dimensions elicited by the initial script.

The analysis was conducted in three sequential steps independently by the four researchers who carried out the interviews. First, each researcher attached labels to segments of data that depicted units of significance while bearing in mind the structuring dimensions that were developed in the preparation of scripts for the interviews. The extraction of the 
gradually emergent main themes enabled the filtering and the sorting of the collected data, enabled making posterior comparisons with other segments of the discourses. The purpose was to ensure that the essential contents were preserved, but a manageable short text was produced. Subsequently, interresearcher agreement was achieved so any differences found could be reconciled for each code and both formed together the categories and dimensions that emerged from the material. Then, the final set of dimensions and categories were once again compared with the ones that supported the scripts for the interviews to assure that the main questions, which guided the data collection, were answered by the analysis (Mayring, 2004).

The generated themes, which are grounded in empirical data, presented in this article are professional trajectory, professional self-identification with sexology, sex education, sexual medicine and sex therapy, pharmaceuticalization of sexology, sexological perspectives on gender, and the journey of sexology.

\section{Results}

\section{A Profession?}

The first major consensus among the interviewees was that they considered that sexology, as a scientific knowledge, has a multidisciplinary main characteristic; and the second was that sexology was not considered a profession in itself but was mainly seen as a secondary main professional specialization. The fact that there was no academic recognition of sexology was also associated with an absence of the pursuit of an academic career: "I identify myself as a psychiatrist who later got a subspecialty in sexology, which did not exist in the Medical Association, nor was officially recognized in Portugal. This was an option that did not correspond to any university career" (male psychiatrist, first generation).

As can be inferred by the following quote of a male social scientist of the first generation of sexologists, the multidisciplinarity and the multiprofessionality are two sides of the same coin:

I don't designate myself as a sexologist, and I don't like being called a sexologist. There are people who call themselves sexologists. Because I consider that sexology is an interdisciplinary area, there may be physician-sexologists, sociologist-sexologists, lawyer-sexologists, anthropologistsexologists, and psychologist-sexologists. I do not think that sexology is a profession. I consider that a sex therapist can approach a profession, although I consider that one should be considered a psychotherapist and not specifically a sex therapist. (male social scientist, first generation)

A distinction between sexology and sex therapy emerged in almost all the participants' discourses, the latter being the professionalized area of practice in the field of sexology, as illustrated by a male psychologist of the second generation: "It is difficult to define a sexologist: 'one should not close it in a box.' In relation to a sex therapist, it is already possible to establish rules: training in sexology and in the area of sexual difficulties must have a clinical practice. Ideally, a sex therapist must have training in psychotherapy, even physicians."

Training is in fact another aspect that influences social and self-representation of sexology as a professional activity. Authority and recognition depend on academic and practical training:

I'm a clinical psychologist, researcher, and sexologist. A sexologist is someone who has clinical training, did a specialization in the area of human sexuality, and has done theoretical and practical training with supervision. A sexologist ideally would have training in areas of knowledge [such] as medicine, psychology, anthropology, and sociology. This is a life[time] journey acquired throughout the academic and clinical path. (female psychologist, second generation)

Even though both physicians and nonphysicians attribute value and pursue specializations in sexology, the self-recognition of sexology as a professional identity varies among them, and is used especially by nonmedical professionals, as illustrated by the following quote from a female gynecologist:

I'm also a sexologist. We, doctors, have some reluctance to accept the title. Because sexuality has taboos and so do we. Sexual medicine for doctors is a well-accepted thing, and another tentacle of gynecology; sexology comes from sex, it is yet another word. But it's true, I am also a sexologist; in fact, it's what I do too. Even without wanting to and trying to defend myself and move toward sexual medicine.

\section{Tensions in the Field: Sex Education, Sexual Medicine, and Sex Therapy}

There is one major division emerging from sexologists' discourses: clinical versus sex education narratives, as expressed by the following quote: "Sex education is a completely different area to this [the clinical practice]. It is another world. It's something that I am not interested in. First, I am skeptical about sex education" (male urologist, second generation).

This division has existed since the beginning of Portuguese sexology in the 1970s, and it is still prevalent, corresponding to a separation of professionals and also of scientific societies in the field of sexology:

In Portugal there is a historical link of sexologists with sex education, especially via the Family Planning Association [APF] and not via SPSC. Because APF appeared earlier and many were militants of APF before the founding of SPSC ..., there was a division of labor between the SPSC, which was founded in 1984 and was devoted to clinical issues, as the name indicates ... Nowadays, it remains the same. (male social scientist, first generation) 
In fact, this distinction is linked to a separation of areas of expertise: sex education, sexual medicine, and sex therapy. The sexology transdisciplinary master's degree of Lusófona University (in Lisbon, Portugal) is separated into three major specializations: sexual medicine for physicians; sexual psychology for psychologists; and human sexuality for social scientists, nurses, educators, and others. Both physicians and psychologists can do research, training, and clinical practice, while social scientists can do research and training mostly focused on sex education.

The physicians prefer the term sexual medicine, and social scientists state that sexology is a broader area of knowledge, which has always been connected to social sciences. According to a first-generation male social scientist, "Sexual medicine cannot be confused with sexology. The life of the study of human sexuality is deeply tangled with the social sciences, particularly sociology and anthropology." But, in fact, sexual medicine represents a broader area for physicians' practice, compared to andrology, as expressed by a male urologist: "I specialized in urology, and early on I dedicated a lot to andrology. Now, I don't like this term so much. I prefer sexual medicine, because andrology limited what I always really liked - it restricted me just to sex."

For psychologists who practice both in the sexual medicine and sex education areas, but also mainly in sex therapy, sexology is the hat that fits: "I believe that sexual medicine has grown with the pharmaceutical industry, which contributed to further research but has been an opening for other perspectives" (male psychologist, second generation). And though sexology in Portugal had psychiatrists as its fundamental pioneers, psychologists were soon called to help them in the first consultations:

Sexology at its start had a very strong psychiatric component that is more than psychological. Psychologists were, I say, the helpers of psychiatrists. Who were the founders? Psychiatrists - all of them. Because psychologists also worked in these consultations, since its beginning the Sexology Society [SPSC] also involved psychologists. (male social scientist, first generation)

Those professionals still work together today in sexology consultations in hospitals, which also include other medical specialties on the clinical team, such as endocrinologists, as noted by the following male interviewee who is an endocrinologist: "We work in partnership ... I have had a lot of support and collaboration. I have learned a lot from these professionals ... A multidisciplinary approach is fundamental in sexology."

Psychologists working in hospitals corroborated this positive evaluation of a multidisciplinary collaboration in sexology:

Even when the doctor considers that it is necessary to take a drug for erectile dysfunction or premature ejaculation, it is always preceded by a psychological consultation. That's where a therapeutic plan is established with the patient, and the beginning of what will be the "journey" that they will take together, the perception of what the symptom means and the reasons that led to the appointment ... The consultation is an integrated team, the relationship couldn't be better. It is a true collaboration. (female psychologist, second generation)

However, these collaborative teams are less frequent outside of hospital services:

There are two types of clinical practice, which are in hospitals and the private practice. In hospitals, it is easier to work with multidisciplinary teams because the patient does not pay for each consultation, or [he/she] pays marginally, so it's easier to work as a team. I've always had psychologists and psychiatrists who were interested in me and whom I am interested in this field. In private practice, obviously, the first approach is we try to solve the problem by ourselves and then, if needed, [we] ask for help. (male endocrinologist, first generation)

In reality, outside of sexology consultations, referrals to other specialists seem to be less frequent: "There are few physicians referring to psychologists, because they don't understand that there are psychological and double bases to explain the problems" (female psychologist, second generation). In addition, the growing idea that sexual dysfunctions are predominantly organic limits the referral to psychologists or even psychiatrics, as in the following male gynecologist's statement: "A lot of my colleagues, if they had a woman without desire, would send her to a psychiatrist. I think that is complete nonsense, because eighty percent of the complaints - frigidity, anorgasmia, postpartum frigidity, [and] dyspareunia-none of these are psychiatric."

\section{Pharmaceuticalization and Naturalization of Sexuality in Portuguese Sexology}

Medicalization and pharmaceuticalization (Abraham, 2010; Conrad, 1992; Williams et al., 2011) introduced a new dynamic in the field of sexology, and different positions exist concerning the impact of the pharmacological management of erectile dysfunction, such as oral sildenafil citrate, on the field.

First, there was an accentuation of the redistribution of powers among the different professionals in the field. If endocrinology had a strong influence at the beginning through the Portuguese Andrology Society (SPA, or Sociedade Portuguesa de Andrologia), urology will become as strongest working force, as it can be understood by the following quote of a first generation endocrinologist:

Currently, the SPA could be named Portuguese Society of Sexual Impotence ... Initially, the treatment of sexual dysfunction was very psychological, with the psychiatrists. Then when drugs came, medicalization began... . This was caught by urology, both here and worldwide. People who do research are mostly urologists. And they forgot that andrology is all of this.

In fact, not only have urologists taken a leading position in the field, but there was also a narrowing into the biological 
and medical, often felt by a sense of the lost essence of sexology.

I'm old school $\ldots$ before there were pharmacological therapies ... Viagra, whether we like it or not, is a milestone in the history of sexology. I continue to appreciate the breadth of knowledge in sexology. Otherwise, it is reductionist ... I don't give up on the other side, which at the beginning, when I started doing sexology, was valued by my masters, and continues to be valued by me. I think now the training is more reduced to biological and medical sciences. And sometimes we lose, because they do not look at the individual, at the social context, [at] the cultural context. (female psychiatrist, second generation)

Second, the expression "sexual revolution" used to describe the introduction of Viagra seems exaggerated - especially compared to the sexual revolution that accompanied the advent of the birth control pill: "Viagra was a media topic. There was no sexual revolution. Viagra is an instrument of erectile dysfunction, a medicine. But it brought important changes at the level of sexual behaviors of the elderly" (male social scientist, first generation).

Nevertheless, the term "sexual revolution" (Hekma \& Giami, 2014) is somehow used, and the idea that it is generalized as seeking help seems to be more or less consensual:

It's not a social humiliation to see a doctor to confess a particular problem of erectile dysfunction or other. And if you go back a few decades, it was unthinkable. And that's why I was comparing to mental illness. Nowadays, to say that one has a depression is almost commonplace. And a few years ago, it wouldn't be, it would be almost a taboo. The same applies to the field of sexology [and] of sexual therapy. (female social scientist, second generation)

Associated with this "normalization" of sexual dysfunction in men is the perspective that men increased their ability to expose their sexual difficulties and reveal information about their sexual lives.

Viagra, in Portugal, was launched in November 1998. It was a fantastic landmark. Not [only] because it was a pharmacological landmark, which it was. It was a pharmacological revolution. A very effective medicine appeared, but a physiological one. But more than a pharmacological revolution, it was a cultural revolution. From that moment, it became a disease with a treatment, and patients began to come to the doctor spontaneously. This revolution hasn't existed in women... . In order for female Viagra to provoke a pharmacological and cultural revolution, I don't believe it. The woman is too complicated; female sexuality is too complicated. (male urologist, second generation)

This last statement also seems to indicate a pharmaceuticalization effect of raising expectations for physicians and male patients, yet without the same "cultural revolution" for women's sexuality.
Less explicit seems to be the link to the social and cultural context and the challenging of "normal" standard of sexual life, with the understanding that there are different sexualities that the Viagra phenomenon covered in a "McDonaldization of sex" process (Tiefer, 2004a):

The therapeutic arsenal brings great benefits for many people, particularly for those who want to use it, but not always the same benefits to the other person [of the couple] or to his own ... There are people who have a poor sex life, but they're okay with it; it's not a problem for them. By what right do we have to impose a standard that is a social pattern, a cultural pattern? (male physician, second generation)

Sexology, as a scientific knowledge, somehow risks being consumed by the influence of medicalization and pharmaceuticalization of sexuality:

In the SPSC, there were great discussions about who could be a member. Because when it is named Clinical Sexology Society, we must surrender to the evidence that only those who can practice clinic can be members... . But if we compare with sexual medicine societies, we are an extraordinary breadth. The name itself is curious. What does sexual medicine mean? ... We speak of anthropology of sexuality, sociology of sexuality; it doesn't cross your mind to say sexual anthropology or sexual sociology. But medicine is imperialistic. (male psychiatrist, first generation)

\section{The Journey of Sexology in the Sexologists' Perspectives: A Discipline or a Multidiscipline?}

The limits of sexology are society's evolution, the sexologists' skills and practice, and the social organization of the profession (Giami, 2012). Such limits are perceived as minimally constraining by the Portuguese sexologists:

[Sexology] technically can be much more empowered than it was a few decades ago, when it comes to prescribing certain conduct or to intervene directly on the reproductive system, either surgically or with auxiliary sexual relationship. But increasingly there is the understanding that what has always been learned by us as the biopsychosocial aspects of sexuality, that was just a buzzword, a bottomless thing, and that people hardly understand without knowing the cultural location in which we grew up. (male physician, second generation)

Sexology as a transdisciplinary field is a promised land, as noted by a female psychologist of the second generation:

In theory, in academia, there is a desire for transdisciplinarity and multidisciplinarity. I speak to some colleagues, saying that I've been told that I was going to work in multidisciplinary teams and such cooperation on the basis of the objectives that we want to achieve would exist ... In practice, I think that there are many obstacles for that to happen.

Among the obstacles pointed out are indeed organizational and economic-related factors, but there are also socially and 
culturally rooted issues, in particular the conservative fascist government that was in office until the democratic revolution of 1974 and was anchored in the Catholic religion, where the cult of the figure of the Virgin Mary was seen as a castrating force for women's sexuality and one of the main pillars of machismo.

The main challenges identified by the key professionals interviewed concerned the different areas of practice: research, clinical practice, and training. In terms of research, despite Portuguese social scientists having always been involved in some of the major sexuality investigations, there also seems to be a long way to go, not only in terms of the themes investigated but also in acceptance in the social science field. The growing recognition of tangled fields can also be a way of developing the field of sexology:

There's a long way to go. It also includes legitimizing the fields of gender studies, feminist studies, [and] LGBT studies. In the first two examples, there are masters and $\mathrm{PhD}$ programs; there is an offer, albeit reduced, in Lisbon and Coimbra. In the LGBT area, it does not exist. It is still an empty space... . Things are moving; there are more and more people working in this area. A closer collaboration between feminist studies and the LGBT area is crucial. (female social scientist, second generation)

There is also the recognition that research would help the other areas of practice to develop, namely, the improvement of the clinical practice:

I would study the sexuality of sexual minorities ... More easily there is a campaign to prevent HIV/AIDS, in a medical preventive perspective, than how to practice anal sex with greater security, greater pleasure ... This is the side that also interests me in sexology and that can also help people who I get in clinic. (female psychologist, second generation)

And clinical practice also struggles with the recognition of its importance in the medical or therapeutic field:

Sexology continues to be the poor relation; if psychiatry is poor, then sexology is extremely poor. Poverty is greater in the institutions. It has nothing to do with poverty either of the patients or of the theme. It has [something] to do with the institutions, which continue to depreciate sexology a lot, which is an extremely important area for patients. And we feel that in our skin, since I have a huge backlog of appointments for consultations. (male psychiatrist, second generation)

\section{Discussion}

\section{Professional Self-Identification to Sexology}

The professional legitimacy of sex therapists, as well as sexologists, is an important and controversial topic, as shown by peer commentaries (Bancroft, 2009; Kleinplatz, 2009; Štulhofer \& Arbanas, 2009; Tiefer, 2009) on Binik and Meana's (2009) essay on the current state and possible future of sex therapy. Sex therapy is an ambiguous term, and even from a patient or client perspective it is not clear who sex therapists are or what they offer. Is a sex therapist a trained psychologist, a physician, or even a nonprofessional? In Europe, this term has been replaced by sexologist to represent clinicians, from various specialties, with further training in the treatment of sexual disorders (Giami \& de Colomby, 2006). Some of the ambiguity is because of the nature of sexual concerns, as they cannot simply be seen as psychogenic (addressed by psychologists and psychotherapists) or organic (addressed by physicians and physical therapists), and the whole person/couple needs to be taken into account when dealing with a sexual problem (Nasserzadeh, 2009). Unlike physicians, psychologists, and other professions that have been defined through profession laws and government approvals, there is no official registration or regulation of who is entitled to present himself or herself as a sexologist. Training programs and international rules for the practice of sexology are in process (Kontula, 2011; Porto, 2006; Pryor, 2006).

After a century of development in the field of sexology and decades of attempts to establish the field of sexual medicine, in 2011 the Multidisciplinary Joint Committee of Sexual Medicine established the curriculum for training, recommendations of care, and assessment of physicians in the field of sexual medicine (Reisman, Eardley, Porst, \& Multidisciplinary Joint Committee on Sexual Medicine, 2013). Although this qualification is not a license to practice sexual medicine, it offers professional recognition for those practicing or wishing to practice in the field of sexual medicine (Arbanas, Reisman, \& Andrews, 2015). The professional characteristics and motivational factors of these sexual medicine specialists reveal a wide diversity regarding their country of origin, religious background, years spent in the field of sexual medicine, time frame of their work, and the sexual problems with which they work. Therefore, the sociocultural context and diversity of the professionals and patients should be taken into consideration (Arbanas et al., 2015).

As explained by Giami and Russo (2013), investigations concerning the field of sexology have a double relevance. On one hand, they provide a comprehensive view of how sexuality is addressed by diverse experts on the subject. As such, they have the potential of contributing to the formulation of public policy regarding the control and prevention of sexually transmitted diseases, the promotion of sex education in schools, and the development of sexual health as a specific field. On the other hand, they enable the understanding of dominant conceptions of sexuality and of the definitions of normal/functional and pathological/dysfunctional sexuality, and they may foster a consistent and critical discussion about the application of policies, theories, and practices (Brigeiro \& Facundo, 2013).

Social and legal recognition of sexology as a profession is linked to the acquisition and validation of knowledge through academic training. Without a broader academic 
education, in particular the existence of postgraduate and doctoral degrees in sexology in Portugal, the institutionalization and academic legitimacy of sexology remains incomplete. Indeed, most specializations in sexology remain outside the universities or in the hands of the most prestigious institutions and specialties in the academic and professional areas. Sexology has not yet become a specific academic territory in Portugal and is still being constructed as a form of "dirty work" via the systematic practices of the university system imposing stigma effects that are not simply individual but constitute persistent patterns of institutional inequality (Irvine, 2014).

Sexologists and sexual health experts may choose, as many Portuguese sexologists do, social scientists and psychologists in particular, not to comply with "intellectual and political marginalization" (Tiefer, 2009) and get involved in the sexual promotion of sexual health focusing not only on its biomedical but also social dimensions. Interdisciplinary and overlapping fields of sexuality and LGBT and queer studies have been flourishing in Portugal, which are intimately bound with feminist, queer, and AIDS research and activism, and trans activism, indicating the field dynamics.

\section{The Gap Between Sex Education, Sexual Medicine, and Sex Therapy}

Portuguese sexologists view sexology as unified in its definition but multiple in its clinical and therapeutic practices, which constitutes the challenge of its identity but also the richness of its potential vision of sexuality and social theory. Sexology in Portugal is, however, still fragmented among different disciplines: sometimes close in practice and collaborations, nevertheless far away in cooperation and articulation in some cases, services, and professionals. Each and every perspective has sexuality as a scientific object, and sexology must embrace them all, and also their interdisciplinary practice, to establish it as a transdiscipline, different from each of the bordering domains. A qualitative study with sexologist members of the Swedish Association for Sexology also pointed to different groups of sexologists in the sexology landscape (Löfgren-Mårtenson, 2015) and highlighted the need for an interdisciplinary approach among sexologists (Dupras, 2010). The principal similarity between sexology realities in the two countries lies between the Portuguese and the Swedish so-called pioneers, both in terms of its basic training (physicians) and the activities (creation of associations, training, and clinical queries) and even in the strong dedication to sexology. Another common aspect relates to the recognition and valuation of the research's potential value in sexology.

The gap found in Portugal between sex educators and clinical sexologists can be related to this distance from activism and sexual health promotion, which requires public and visible values on such critical issues as abortion (legally permitted on the women's will in 2007) and LGBT rights, among others.
Sexological practice in Mexico has searched for the production and installation of a normative order of sexuality based on scientific knowledge, especially through a biomedical vision. Sexological discourse has also gained an elevated position in the field of human rights, especially with regard to sexual diversity, suggesting the possibility of wider alliances with social movements (Alcántara \& Szasz, 2012). This dual movement is also in place in Portuguese sexology. The new "broadly trained sexologist" will be able to produce better research, education, and clinical work (Cacchioni \& Tiefer, 2012).

Also, the descriptions presented in the case of Colombia identify the role that certain professionals played in transforming a whole system of sexuality and also identify the obstacles they faced (Brigeiro \& Facundo, 2013). Some of the Portuguese narratives in each of the areas of practice also illustrate this reflexive and activist aspect of sexology not exempt from difficulties and barriers against homophobia and heterosexism (Moita, 2006), framed within a heteronormative conception of gender that oversimplified malefemale difference, and ignored differences and exclusions within the gender categories.

Quoting Giami and Russo's (2013) work: “The presence of the sexual health and sexual rights perspectives in the field of sexuality will help to maintain the ideals developed in the 1930s in Western Europe, with the World League for Sexual Reform, which linked medical psychological approaches to sexuality and the idea that sexuality can contribute to human and social emancipation" (p. 10). This was a cherished thought for some Portuguese sexologists. Nevertheless, as Lottes (2013) said in her discussion of the principles of human rights and rights-based approaches to sexual health policies, rights principles should be integrated into sexuality fields. The Portuguese case also illustrates well the desire for a seed of change in the scenario of a more participatory, inclusive, and queer academia (Santos, 2006). In fact, although there is growing concern regarding health and human rights issues in sexuality research, more investment is necessary to scientifically strengthen the domain worldwide. As an example of this, Mpinga, Verloo, London, and Chastonay's (2011) literature review of three of the major sexuality journals (Archives of Sexual Behavior, Journal of Sex and Marital Therapy, and Journal of Sex Research), covering the period from 1999 to 2008, found only six articles about health and human rights.

As Tiefer (2002) urged sexology professionals to actively promote sexual rights as human rights to avoid sexual rights discourse to remain empty rhetoric, Lottes (2013) illustrated how educators, researchers, and therapists can integrate sexual rights principles into their teaching, professional education, ethical codes, and theoretical frameworks. Furthermore, Parker and collaborators (2004) demonstrated that the increased use of sexual rights frameworks, such as the HIV/AIDS epidemic, sexual exploitation and violence, stigma and discrimination of sexual and gender minorities, prostitution, pedophilia, and sex trafficking, has given 
support to "an explicit politicization of research and the engagement of researchers in social justice causes" (p. 362).

\section{The Influence of the Medicalization and Pharmaceuticalization of Sexuality}

The approach and discussion of the so-called process of medicalization of sexuality is critical to contextualize the constitution of the field of sexology as well as the professional activity of the sexologist (Giami, 2007, 2009; Rohden, 2009, 2012; Russo, 2013; Tiefer, 1996; Weeks, 2002). The medicalization of sexuality includes, in a structural and dynamic approach, the organization of knowledge, social organizations, the organization of professions and of the actors involved, as well as the subjectivities. This set comprises what Foucault (1978) called the "apparatus of sexuality," which enables the understanding of sexuality as being produced and reinvented by institutions with the power of classification, regulation and separation between the normal and the deviant, the sane and the sick, and so on.

Sexology's strengthening is in fact associated with the increasing medicalization of the field of sexology, intensified by the release and commercialization in the 1990s of Viagra, and by the fact that some sexual behaviors and states are defined as "health problems" that need medical and/or pharmaceutical drugs intervention (Loe, 2004; Marshall, 2002; Wentzell, 2013). It also has to do with the organization and the institutionalization of sexologists as professionals, marked by the development of new scientific and professional societies and the development of academic teaching, which are progressively recognized by the academic and health system. This set of dimensions may explain the current development of sex therapies.

The reconceptualization of erectile dysfunction as an organic dysfunction and the relative abandonment of the psychogenic model, with the advent of Viagra, did not spur the same scientific discussion generated at the time of the application of the same organic/biological model of sexual function to female sexual dysfunctions. This dominant model of sexuality seeks to reduce men's bodily and sexual experiences to a universal model of male (hetero-) sexuality. It exemplifies the reinforcing of the stereotypical, commonsense picture about male sexuality as organically driven, in opposition to female sexual function, determined by the social, psychological, and interpersonal context of female sexual activity and relations (Fishman \& Mamo, 2001; Giami, 2007; Rohden, 2009).

As well defined and illustrated by a special issue of the Journal of Sex Research, medicalization of sex is a current trend that illuminates the importance of a broader view of sexology: "The medicalization of sex is now a complex domain of personal and professional activity at the intersection of technology, culture, professional training, medicine, gender, sexuality, global capitalism, politics, and rapid social change" (Cacchioni \& Tiefer, 2012, p. 307). Therefore, historical and contemporary developments must be seen in association with diverse dimensions of sexual medical diagnosis, treatment, and surveillance, analyzing their advantages and disadvantages for social life, subjectivity, embodiment, and experience.

Our results indicate that sexology, in Portugal as well as worldwide, as a scientific knowledge somehow risks being erased in its practice by the influence of medicalization and pharmaceuticalization of sexuality. As pointed out by Tiefer (2001), the medicalization of sex also generally implies a body-mind compartmentalization, generalizations about human function and experience, and a focus on the individual, creating a universalized function-focused sexuality. Some of the key professionals of the field of sexology in Portugal struggle with the "tyranny of the natural" and to reveal and decode gender meanings and significances (Tiefer, 2004b).

\section{Limitations}

Our findings were based on a purposive sample of key professionals to guarantee generation, gender, discipline, and practice diversity among actors in the field of sexology. Contrary to the qualitative study of sexologists in Sweden (Löfgren-Mårtenson, 2015), not all of our key informants were members of an association for sexology, which we believe has diversified their views of the profession. Nonetheless, it is conceivable that less well-known sexologists and less explicit or emergent professions in the field in Portugal, such as nurses and physiotherapistswhich are visible in other countries such as in Finland (Kontula \& Valkama, 2006), in the United Kingdom (Wylie et al., 2004) and in Sweden (Fugl-Meyer \& Giami, 2006), but seem nonexistent in Portugal-would provide different views of their profession. Thus, continuing research is important to observe new possible trends of the ongoing professionalization process of the field of sexology. Also, sex education is accommodated by different professional and institutional groups, such as NGOs and research groups at universities, with less clearly defined boundaries. This means that it overlaps with activities undertaken by representatives of social movements and encompasses such activities as HIV prevention. The inclusion of sex educators and the analysis of this subfield would overrun the scope of this article; as in Portugal sex educators and sex counselors are not professional specialties, and those doing sex education are mostly recruited among secondary school teachers, who do not recognize themselves as sex educators and even less as sexologists, and they do not come from a sexology perspective or contribute directly to it. Therefore, further research is needed to deepen our understanding of the professionalization process of sexologists. Nevertheless, this study had a high acceptance rate and the sample captured the diversity of key informants' main characteristics considering the important elements of the sexology field in Portugal, including the narratives of founding members. 


\section{Concluding Remarks}

This article discussed how Portuguese sexologists have been defining and legitimizing their own expertise. The Portuguese case illustrates how sexology is a potential transdiscipline, although it can be deeply complex due to its uncertainties (Reiss, 1999). Sexology in Portugal is becoming more visible and earning more public recognition as a professional field. The Portuguese context provided an incentive to talk about sexuality, and so Portuguese sexologists enjoyed what Foucault (1978) called "the speaker's benefit": advantages for those speaking about the prohibited, for example, unacceptable sexuality, and representing themselves as liberating sex from repression through speaking about it (Irvine, 2014).

Although scientific associations and research have developed since the 1970s, most experts do not consider it to be a profession, and medical and psychological societies tend to consider sexuality a marginal area. Because sexology and sex therapy are not yet well-established and well-recognized health care professional activities, endorsement of the professional identity of sexologist in Portugal, as in other European countries (Giami, 2012), is low and may also suggest that the term sexologist is becoming problematic and is no longer accorded the prestige that it was given during the 1930s in Europe (Bland \& Doan, 1999). Portuguese sexuality researchers have also been struggling to establish academic legitimacy in the face of deep cultural anxieties about their subject of study (Irvine, 2014).

The findings indicate that sexology in Portugal, as in other European countries, is not seen as a full-fledged profession but rather as a specialization or as a secondary field of action within the framework of mainstream health professions and even among professionals who are publicly associated with sexology. The sexual medicine area is more prevalent and visible among physicians (urologists, gynecologists, endocrinologists, psychiatrists), thus reflecting the gap between psychosocial and biomedical approaches. A close link between clinical practice and research as well as a gap between clinical practice and sex education and health promotion were found. Cooperation and communication between areas is a shared but unreached aim mainly because of lack in established networking, with some exceptions.

The confluence of the new views on sexuality, along with the social movements, is still challenging the power of sexology to define the normative parameters of sex and gender, offering alternative views about sex and gender grounded in people's own experiences and within a sociopolitical context, especially considering power inequalities between men and women, the concepts of maleness and femaleness and masculinity and femininity. As in the past when they emerged, in the present they remain disruptive of scientific sexology's strategy for professionalization and of the internal self-definition of sexology (Irvine, 2005, 2014; Jackson \& Scott, 2010). This seems to be the main obstacles of sexology in general. How sexologists will continue to react to the new ethical and methodological challenges and become more cross-disciplinary and interdisciplinary is what will define the future of sexology in Portugal.

\section{Acknowledgments}

We would like to acknowledge the three Portuguese associations - the Portuguese Clinical Sexology Association (SPSC: Sociedade Portuguesa de Sexologia Clínica), the Portuguese Association of Andrology (SPA: Sociedade Portuguesa de Andrologia), the Family Planning Association (APF: Associação para o Planeamento da Família) - for all the support that was provided during the implementation of the project; the research team, especially Professor Alberto Galvão Teles, namely for helping contact the participants, and Vera Forjaz, for participating in conducting the interviews. Finally, the authors wish to express gratitude to all the participants of this study.

\section{ORCID}

Violeta Alarcão @ http://orcid.org/0000-0002-4807-5904

\section{References}

Aboim, S. (2013). A Sexualidade dos Portugueses. [The Portuguese sexuality]. Lisbon, Portugal: Fundação Francisco Manuel dos Santos.

Abraham, J. (2010). Pharmaceuticalization of society in context: Theoretical, empirical, and health dimensions. Sociology, 44(4), 603622. doi: $10.1177 / 0038038510369368$

Albuquerque, A. (2010, May). O Hospital Júlio de Matos tem consulta de Sexologia há 34 anos. [The Hospital Júlio de Matos has a clinical sexology practice for 34 years]. Paper presented at Sexology Past, Present, and Future: Celebrating a Century of the Multidisciplinary Science of Sex, European Federation of Sexology Congress, Oporto, Portugal.

Alcántara, E., \& Szasz, I. (2012). Between the local and the global Chronicles for understanding the field of sexology in Mexico. International Journal of Sexual Health, 25(1), 27-46. doi:10.1080/ 19317611.2012.753973

Almaas, E., \& Giami, A. (2006). Sexology as a challenge to the health care system: The Norwegian version. Sexologies, 15(1), 35-43. doi:10.1016/j.sexol.2005.11.009

Almeida, M. V. D. (2010). O contexto LGBT em Portugal. [The LGBT context in Portugal]. In Conceição Nogueira e José Manuel Nogueira (Org.), Estudo sobre a discriminação em função da orientação sexual e da identidade de género [Study on discrimination based on sexual orientation and gender identity] (pp. 45-92). Lisbon, Portugal: CIG.

Arbanas, G., Reisman, Y., \& Andrews, S. (2015). The sociocultural aspects, professional characteristics, and motivational factors of the first fellows of the European Committee of Sexual Medicine. Journal of Sexual Medicine, 12, 1368-1374. doi:10.1111/jsm.12900

Ariès, P., \& Béjin, A. (1985). Western sexuality: Practice and precept in past and present times. New York, NY: Basil Blackwell.

Bancroft, J. (2004). Alfred C. Kinsey and the politics of sex research. Annual Review of Sex Research, 15(1), 1-39.

Bancroft, J. (2009). Sex therapy needs building not deconstruction. Archives of Sexual Behavior, 38(6), 1028-1030. doi:10.1007/s10508-009-9471-0

Binik, Y., \& Meana, M. (2009). The future of sex therapy: Specialization or marginalization? Archives of Sexual Behavior, 38(6), 1016-1027. doi:10.1007/s10508-009-9475-9 
Bland, L., \& Doan, L. (Eds.). (1999). Sexology in culture: Labelling bodies and desires. Cambridge, UK: Polity Press.

Brigeiro, M., \& Facundo, A. (2013). Between avant-garde ideals and conservative moralities: The emergence of sexology in Colombia. International Journal of Sexual Health, 25(1), 75-91. doi:10.1080/ 19317611.2012 .759635

Cacchioni, T., \& Tiefer, L. (2012). Why medicalization? Introduction to the special issue on the medicalization of sex. Journal of Sex Research, 49 (4), 307-310. doi:10.1080/00224499.2012.690112

Charmaz, K. (2003). The grounded theory method: An explication and interpretation. In R. M. Emerson (Ed.), Contemporary field research: A collection of readings (pp. 109-126). Prospect Heights, IL: Waveland Press.

Conrad, P. (1992). Medicalization and social control. Annual Review of Sociology, 18, 209-232. doi:10.1146/annurev.so.18.080192.001233

Dupras, A. (2006). La professionnalisation de la sexologie au Québec. Sexologies-Revue Européenne de Sexologie et de Santé Sexuelle, 15 (1), 58-63.

Fishman, J. R., \& Mamo, L. (2001). What's in a disorder: A cultural analysis of medical and pharmaceutical constructions of male and female sexual dysfunction. Women and Therapy, 24(1-2), 179-193. doi:10.1300/J015v24n01_20

Foucault, M. (1978). The history of sexuality: An introduction. New York, NY: Pantheon Books.

Freidson, E. (1988). Professional powers: A study of the institutionalization of formal knowledge. Chicago, IL: University of Chicago Press.

Fruhstuck, S. (2003). Colonizing sex: Sexology and social control in modern Japan. Berkeley: University of California Press.

Fugl-Meyer, K. S., \& Giami, A. (2006). Swedish clinical sexologists: Who are they? Who do they treat? Sexologies, 15(1), 14-21. doi:10.1016/j. sexol.2005.11.003

Giami, A. (2007). Fonction sexuelle masculine et sexualité féminine. Permanence des représentations du genre en sexologie et en médecine sexuelle. [The male sexual function and female sexuality: The permanence of gender in sexology and sexual medicine]. Communications, 81(1), 135-151. doi:10.3406/comm.2007.2464

Giami, A. (2009). La médicalisation de la sexualité: Fausses questions et vrais enjeux. [The medicalisation of sexuality: Wrong questions and real challenges]. Sexologies, 18(4), 262-264. doi:10.1016/j.sexol.2009.09.002

Giami, A. (2012). The social and professional diversity of sexology and sex therapy in Europe. In K. S. K. Hall \& C. A. Graham (Eds.), Cultural context of sexual pleasure and problems: Psychotherapy with diverse clients (pp. 375-393). London, UK: Routledge.

Giami, A. (2015). Sexuality, health, and human rights: The invention of sexual rights. Sexologies: European Journal of Sexology and Sexual Health, 24(3), e45-e53.

Giami, A., \& de Colomby, P. (2003). Sexology as a profession in France. Archives of Sexual Behavior, 32(4), 371-379. doi:10.1023/ A:1024099117090

Giami, A., \& de Colomby, P. (2006). La profession de sexologue en Europe: Diversité et perspectives communes. [Sexology as a profession in Europe: Differences, diversity and common perspectives]. Sexologies, 15(1), 7-13. doi:10.1016/j.sexol.2005.11.010

Giami, A., \& Russo, J. (2013). The diversity of sexologies in Latin America: Emergence, development, and diversification. International Journal of Sexual Health, 25(1), 1-12. doi:10.1080/19317611.2012.760507

Giddens, A. (1992). The transformation of intimacy: Sexuality, love, and eroticism in modern societies. Darby, PA: Diane Publishing.

Haeberle, E. J. (1981). Swastika, pink triangle, and yellow star: The destruction of sexology and the persecution of homosexuals in Nazi Germany. Journal of Sex Research, 17(3), 270-287. doi:10.1080/ 00224498109551120

Hall, K. S. K., \& Graham, C. A. (2012). Cultural context of sexual pleasure and problems: Psychotherapy with diverse clients. London, UK: Routledge.

Hekma, G., \& Giami, A. (Eds.). (2014). Sexual revolutions. Houndmills, Basingstoke: Palgrave.

Hughes, E. C. (1958). Men and their work. Glencoe, IL: Free Press.

Hughes, E. C. (1962). Good people and dirty work. Social Problems, 10(1), 3-11. doi:10.2307/799402
Irvine, J. M. (2005). Disorders of desire: Sexuality and gender in modern American sexology. Philadelphia, PA: Temple University Press.

Irvine, J. M. (2014). Is sexuality research "dirty work"? Institutionalized stigma in the production of sexual knowledge. Sexualities, 17(5-6), 632-656. doi:10.1177/1363460713516338

Jackson, S., \& Scott, S. (2010). Theorising sexuality. Berkshire, UK: McGraw-Hill Education.

Kleinplatz, P. (2009). Consumer protection is the major purpose of sex therapy certification. Archives of Sexual Behavior, 38(6), 1031-1032. doi:10.1007/s10508-009-9473-y

Kontula, O. (2011). An essential component in promoting sexual health in Europe is training in sexology. International Journal of Sexual Health, 23(3), 168-180. doi:10.1080/19317611.2011.592932

Kontula, O., \& Valkama, S. (2006). Characteristics of the sexology profession in Finland in the beginning of 2000s. Sexologies, 15(1), 22-29. doi:10.1016/j.sexol.2005.11.004

Kristensen, E., \& Giami, A. (2006). Danish sexologists-Who are they and what are they doing? Sexologies, 15(1), 44-49. doi:10.1016/j. sexol.2005.11.002

Loe, M. (2004). The rise of Viagra: How the little blue pill changed sex in America. New York: New York University Press.

Löfgren-Mårtenson, L. (2015). From pioneers to professionals - A qualitative study of sexologists in Sweden. Sexologies, 24(2), e37-e40. doi:10.1016/j.sexol.2014.07.002

Lottes, I. L. (2013). Sexual rights: Meanings, controversies, and sexual health promotion. Journal of Sex Research, 50(3-4), 367-391. doi:10.1080/00224499.2013.764380

Marshall, B. L. (2002). "Hard science": Gendered constructions of sexual dysfunction in the "Viagra Age." Sexualities, 5(2), 131-158. doi:10.1177/1363460702005002001

Mayring, P. (2004). Qualitative content analysis. In U. Flick, E. V. Kardorf, \& I. Steinke (Eds.), A companion to qualitative research (pp. 266-269). London, UK: Sage.

Moita, G. (2006). A patologização da diversidade sexual: Homofobia no discurso de clínicos. [The pathologization of sexual diversity: Homophobia in clinicians' discourse]. Revista Crítica de Ciências Sociais, 76, 53-72. doi:10.4000/rccs.862

Mpinga, E. K., Verloo, H., London, L., \& Chastonay, P. (2011). Health and human rights in scientific literature: A systematic review over a decade. Health and Human Rights, 13(2), E102-E129.

Nasserzadeh, S. (2009). "Sex therapy": A marginalized specialization. Archives of Sexual Behavior, 38(6), 1037-1038. doi:10.1007/s10508-009-9537-z

Parker, R., Di Mauro, D., Filiano, B., Garcia, J., Munoz-Laboy, M., \& Sember, R. (2004). Global transformations and intimate relations in the 21 st century: Social science research on sexuality and the emergence of sexual health and sexual rights frameworks. Annual Review of Sex Research, 15, 362-398.

Porto, R. (2006). Training in sexology in Europe: Past, present, and future. Sexual and Relationship Therapy, 21(3), 281-287. doi:10.1080/ 14681990600815319

Pryor, J. (2006). The European Academy for Sexual Medicine (EASM): The challenge of developing European training standards in sexual medicine. Sexual and Relationship Therapy, 21(3), 273-279. doi:10.1080/14681990600773997

Reisman, Y., Eardley, I., Porst, H., \& Multidisciplinary Joint Committee on Sexual Medicine. (2013). New developments in education and training in sexual medicine. Journal of Sexual Medicine, 10(4), 918-923. doi:10.1111/jsm.2013.10.issue-4

Reiss, I. L. (1999). Evaluating sexual science: Problems and prospects. Annual Review of Sex Research, 10(1), 236-271.

Rohden, F. (2009). Diferenças de gênero e medicalização da sexualidade na criação do diagnóstico das disfunções sexuais. [Differences of gender and medicalization of sexuality in the creation of sexual dysfunctions diagnosis]. Revista Estudos Feministas, 17, 89-109. doi:10.1590/ S0104-026X2009000100006

Rohden, F. (2012). Capturados pelo sexo: A medicalização da sexualidade masculina em dois momentos. [Accessed through sex: The medicalization 


\section{ALARCÃO, BEATO, ALMEIDA, MACHADO, AND GIAMI}

of male sexuality at two different moments]. Ciência \& Saúde Coletiva, 17, 2645-2654. doi:10.1590/S1413-81232012001000014

Russo, J. (2013). A terceira onda sexológica: Medicina sexual e farmacologização da sexualidade. [The third sexological wave: Sexual medicine and the pharmaceutical "treatment" of sexuality]. Sexualidad, Salud y Sociedad: Revista Latinoamericana, 14, 172-194.

Santos, A. C. (2006). Estudos queer: Identidades, contextos, e acção colectiva. [Queer studies: Identities, contexts and collective action]. Revista Crítica de Ciências Sociais, 76, 3-15.

Simonelli, C., Fabrizi, A., Rossi, R., Corica, F., \& Giami, A. (2006). Sexology as a profession in Europe: Results from an Italian survey. Sexologies, 15(1), 50-57. doi:10.1016/j.sexol.2005.11.008

Štulhofer, A., \& Arbanas, G. (2009). Sex therapy in a cultural context. Archives of Sexual Behavior, 38(6), 1044-1045. doi:10.1007/s10508-009-9490-x

Tiefer, L. (1996). The medicalization of sexuality: Conceptual, normative, and professional issues. Annual Review of Sex Research, 7(1), 252-282.

Tiefer, L. (2001). A new view of women's sexual problems: Why new? Why now? Journal of Sex Research, 38(2), 89-96. doi:10.1080/ 00224490109552075

Tiefer, L. (2002). The emerging global discourse of sexual rights. Journal of Sex and Marital Therapy, 28(5), 439-444. doi:10.1080/ 00926230290001592

Tiefer, L. (2004a). The McDonaldization of sex. In L. Tiefer (Ed.), Sex is not a natural act (pp. 99-105). Boulder, CO: Westview Press.
Tiefer, L. (2004b). Pleasure, medicalization, and the tyranny of the natural. In L. Tiefer (Ed.), Sex is not a natural act (pp. 209-217). Boulder, CO: Westview Press.

Tiefer, L. (2009). Misconstruing sex therapy's dilemmas: The need for sexualwissenschaft, sex education, and primary prevention. Archives of Sexual Behavior, 38(6), 1046-1047. doi:10.1007/s10508-0099487-5

Vilar, D. (2009). Contributos para a história das políticas de Saúde Sexual e Reprodutiva em Portugal. [Contributions to the history of sexual and reproductive health policies in Portugal]. e-cadernos CES. Retrieved from https://eces.revues.org/203

Weeks, J. (2002). Sexuality and its discontents: Meanings, myths, and modern sexualities. London, UK: Taylor \& Francis.

Wentzell, E. A. (2013). Maturing masculinities: Aging, chronic illness, and Viagra in Mexico. Durham, NC: Duke University Press.

Williams, S. J., Martin, P., \& Gabe, J. (2011). The pharmaceuticalisation of society? A framework for analysis. Sociology of Health and Illness, 33 (5), 710-725. doi:10.1111/shil.2011.33.issue-5

Wylie, K., de Colomby, P., \& Giami, A. (2004). Sexology as a profession in the United Kingdom. International Journal of Clinical Practice, 58(8), 764-768. doi:10.1111/ijcp.2004.58.issue-8

Zucker, K. (2002). From the Editor's desk: Receiving the torch in the era of sexology's renaissance. Archives of Sexual Behavior, 31(1), 1-6. doi:10.1023/A:1014047701222 